\title{
O processo explosivo do bandoneón na formatação do tango
}

\author{
Paulo Roberto Masella Lopes
}

Resumo: Processo explosivo é o termo utilizado por lúri Lótman para descrever as mudanças qualitativas que ocorrem em um sistema de comunicação e cultura pela introdução de uma informação nova, forçando-o a reestruturar seus estratos semióticos. Diversamente dos processos graduais, os explosivos são imprevistos e, em certa medida, intraduzíveis, expressando a condição de ambiguidade da fronteira que realiza a função tradutória entre o próprio e o estrangeiro. Neste artigo, busca-se associar o estrangeiro bandoneón ao processo explosivo que teria formatado o tango, atribuindo-lhe um traço distintivo que perdura até hoje como um signo próprio do tango.

Palavras-chave: semiótica da cultura; epistemologia da comunicação; música; fronteira; estrangeiro.

Abstract: Bandoneón's explosive process in tango's formatting - Explosive Process is the term used by Yuri Lotman to describe the qualitative changes that occur by introducing new information in a system of communication and culture, forcing it to restructure its semiotic layers. Unlike the gradual processes, explosives are unexpected and, to some extent, untranslatable, expressing the condition of ambiguity of boundaries which accomplishes the translating function between the own and the stranger. In this paper, we seek to associate the stranger bandoneón to the explosive process that would have formatted the tango, assigning it a distinctive feature that remains today as a sign of tango.

Keywords: cultural semiotics; communication epistemology; music; border; stranger.

\section{A jornada do bandoneón}

No que ficou conhecido por Astor's speech, gravado no álbum The Central Park Concert de 1987, ao apresentar-se ao seu público em Nova lorque, o compositor argentino Astor Piazzolla lembra também a jornada do bandoneón, instrumento que é a assinatura do tango. 
Esta é a nova música de Buenos Aires, o nuevo tango. Nós iniciamos com essa música em 1954. [...] Meu nome é Astor Piazzolla, eu nasci na Argentina, cresci em Nova lorque e meus pais vieram de Trani, Itália. Este estranho instrumento que vocês veem aqui e que muita gente diz que é um acordeão, não é um acordeão, é um bandoneón. Este é um instrumento que foi inventado na Alemanha, em 1854, para tocar música religiosa numa igreja. Começou numa igreja e, então, alguns anos depois, foi levado para os bordéis de Buenos Aires. E, agora, é levado para o Central Park. É uma interessante jornada para um instrumento. E vejam, isso não é uma piada, eu não estou tentando ser engraçado, essa é a vida real deste instrumento, uma vida muito surrealista, mas é assim que o tango nasceu (PIAZZOLLA, 1987, faixa 5, tradução nossa).

De alguma forma, esse trecho sintetiza a forma canônica com que o bandoneón é concebido: como uma jornada de um instrumento estrangeiro que se faz próprio. O curioso percurso do bandoneón que Piazzolla descreve marca o papel fundamental que o estrangeiro desempenha na comunicação. De como o distante, o diferente e o estranho contribuem para formatar um espaço semiótico através do qual uma determinada cultura se assenta, mas também se coloca em movimento ao traduzir sistematicamente as informações que vêm de fora lhes outorgando sentido a partir de um novo arranjo em que o era antes ruído, incógnita, excitação - quando não raramente rechaço e recusa - torna-se próprio, articulado em um sistema coerente, ainda que heterogêneo, de combinações de signos.

A jornada do bandoneón no espaço semiótico do tango é enigmática e explosiva. Enigmática, pois poderia ter havido tango sem o bandoneón, poderá haver tango sem bandoneón, mas dificilmente há tango sem bandoneón na medida em que seu timbre evoca o próprio tango, e este se ressente de sua ausência. Esse enigma, do ponto de vista musical, é o que confere ao tango um traço distintivo, possibilitando uma memória sonora sem a qual não haveria propriamente um espaço semiótico através do qual os fluxos comunicacionais do tango fizessem sentido. Explosiva, pois o bandoneón adquire um sentido absolutamente novo ao ser transladado de seu contexto europeu ao do tango, assim como o próprio tango contrai um sentido original ao traduzir sua sonoridade em própria.

A jornada do bandoneón descrita por Piazzolla caracteriza o que Lótman (1999) chama de processo explosivo porque ocorre de forma intempestiva e imprevista, assegurando inovação à dinâmica cultural. O modelo estrutural do espaço semiótico permite que o bandoneón seja modelizado ${ }^{1}$ ao ser introduzido no sistema-tango, enquanto adquire uma função estruturante ao combinar diversos signos, linguagens e textos em uma forma própria, com traços distintivos marcantes, atribuindo uma particularidade que, se antes faltava ao tango, a partir de então, será capaz de lhe garantir certa homogeneidade,

1 A partir da perspectiva da semiótica desenvolvida por Lótman, a modelização pode ser entendida como um processo tradutório ou transformador da linguagem, confundindo-se com o próprio conceito de semiose. Modelizar significa, portanto, transformar a linguagem ou o sentido de um texto de cultura a partir da passagem de um sistema de signos a outro ou pela mudança de contexto. 
certa aparência de unidade e de autenticidade. Trata-se, portanto, de um instrumento que, inicialmente estrangeiro ao sistema-tango, irá se transformar no seu signo mais próprio.

O percurso que o bandoneón traça no espaço semiótico do tango é também de um movimento desde fora até dentro. Ruas e bairros; amores e abandonos; amigos e amantes; morte e solidão; cafés, tabaco e tragos; pampa e gaúchos; Buenos Aires, Paris. Todos esses lugares, sentimentos e personagens adquirem uma qualidade propriamente semiótica quando são traduzidos pelo ar que vibra em seus foles. Tudo se torna movimento contínuo, quando signos que outrora estavam dispersos se reúnem em torno do tango, e o tango modeliza-se em torno do bandoneón. Quando passa o ar pelo bandoneón, o que era antes signo na cultura se torna signo do tango, inserido em um meio comunicante comum.

O gaúcho, por exemplo, já se constituía num personagem próprio à cultura dos pampas, assim como Paris uma espécie de Meca da elite portenha, quando a sonoridade do bandoneón passa a reunir esses signos sob o mesmo contexto do tango. O violino, a flauta e a guitarra [violão] também já ensaiavam uma sonoridade própria ao tango, quando a improvável chegada do bandoneón vai estabelecer uma nova hierarquia instrumental, organizando em torno de si não apenas os sons dos demais instrumentos, mas os lugares, as histórias e os sentimentos na produção de um espaço semiótico que se expande como memória de uma cultura.

Inicialmente, Piazzolla deixa claro que "este estranho instrumento" não é um acordeão, é um bandoneón. Considerando-se que o concerto no Central Park teve lugar em 1987, o estranho talvez fosse o fato de que o bandoneón ainda precisasse ser introduzido para uma audiência supostamente cosmopolita, já que contava com mais de um século de existência e cerca de oitenta anos de convivência mais estreita com o tango.

Por outro lado, Piazzolla dispensa de apresentação os demais instrumentos de seu quinteto, que era composto na época por piano, violino, guitarra elétrica e contrabaixo, restando ao bandoneón a condição de típico, exótico, estranho e estrangeiro. A descrição da jornada desse instrumento é sintomática, pois não mobiliza apenas o percurso do principal signo do tango em sua gênese histórica e social, como relata em sua dinâmica entre o próprio e o estrangeiro a formação de um espaço semiótico. Uma dinâmica que exemplifica a função do estrangeiro na comunicação como condição de possibilidade de engendramento de novos sentidos como aquele que vai traduzir a diversidade sonora e rítmica que aflui à região do estuário do Rio da Prata, no final do século XIX, em uma linguagem própria por meio de um instrumento que lhe imprime um traço distintivo, de tal modo que não apenas sua história, mas essencialmente sua sonoridade, confunda-se com a do tango.

Sábato (2005, p. 24, tradução nossa) assim descreve esse momento: "até que aparece o bandoneón, selando definitivamente a grande criação inconsciente e popular. O tango ia alcançar agora aquilo a que estava destinado, o que São Tomás chamaria 'o que era antes de ser', a quidditas [essência; natureza] do tango". Ou, recuando da escolástica às justas origens da metafísica aristotélica para dela tomar, e torcer, os conceitos de ato e potência, pensar o bandoneón como potência atualizada do - e no - tango. 
No tango, posto que seja no contexto das relações semióticas que se movem em torno do Rio da Prata que o bandoneón vai atualizar seu potencial sonoro e rítmico, cumprindo dentro do sistema-tango uma função central ao lhe fornecer alguns de seus traços distintivos. Embora de origem germânica, é no contexto rio-platense que sua sonoridade adquire uma especificidade que não formata apenas o tango como um sistema de cultura, como a si mesmo enquanto instrumento que expande seu potencial rítmico na medida em que desenvolve uma sintaxe musical própria.

\section{Um signo sonoro e urbano}

A hipótese de que o bandoneón venha a ocupar um lugar central no sistema cultural do tango se sustenta em dois eixos: um que trata das qualidades semióticas decorrentes do timbre do próprio instrumento e que lhe conferem um caráter distintivo, respondendo por uma sintaxe igualmente original do tango. Outro que situa o tango como fenômeno urbano a partir da simultaneidade entre eventos sociais decorrentes dos fluxos migratórios que se colocam em movimento a partir do final do século XIX, tendo o bandoneón como instrumento central para a consolidação desse processo.

Essa centralidade que o bandoneón ocupa no sistema-tango detém-se, portanto, na análise dessas duas hipóteses. Enquanto a primeira busca entender como as qualidades únicas de seu timbre conferem ao tango um traço diferencial, como sua capacidade de instrumento tradutor vai produzir uma sintaxe original, e como em sua vocação híbrida vai conciliar elementos do sagrado e do profano; a segunda procura compreender como seu processo explosivo determina uma condição espacial ao tango por delimitar tanto as fronteiras de seu espaço semiótico como dos limites territoriais entre um mundo urbano e outro rural.

Nesse caso, observa-se a absorção de ritmos que contribuíram na gestação do tango ao deslocá-los de seu contexto rural e folclórico para o âmbito urbano, como também dos ritmos europeus, trazidos pelos imigrantes, em um movimento em direção ao centro no qual o bandoneón desempenhou uma função centrípeta determinante. Essa dinâmica espacial expressa um progressivo movimento que parte do campo à cidade, do arrabal ao centro. Assim, elementos rítmicos da milonga e do chamamé são traduzidos na interação de padrões rítmicos, propiciando novas combinações e um consequente ganho qualitativo ao sistema, de modo que se possa perceber na linguagem do tango resíduos dessas como de outras sonoridades.

E na medida em que alguns desses ritmos remetem ao campo, ao interior, observa-se também a faísca das representações sociais que eles conduzem. Na produção do espaço semiótico do tango, cruzam-se as duas hipóteses: as qualidades semióticas do bandoneón devem se encontrar com as condições históricas e geográficas de sua inserção no contexto urbano, conferindo-lhe um caráter distintivo.

Nesse movimento centrípeto do tango, nota-se ainda como o bandoneón desloca um instrumento emblemático como a guitarra da estrutura rítmica do tango, desferindo 
um duro golpe às representações sociais que esta então conduzia. ${ }^{2}$ De acordo com Sierra (2010) e Zucchi (1998), as formações instrumentais originais dos trios que compunham os chamados conjuntos primitivos, ainda no século XIX, alternavam violino, flauta e harpa com a eventual inclusão do acordeão ou do bandolim, ou ainda da concertina ou da gaita. A melodia era executada em uníssono pelo violino e flauta, cabendo à guitarra a marcação rítmica, ainda que não desempenhasse o papel de solista.

Mas a fisionomia dos tercetos experimentou em pouco tempo uma transformação muito rápida. A guitarra, antigo instrumento de seis cordas introduzido nestas terras [argentinas] pelos colonizadores espanhóis e payadores regionais, incorporou-se ao tango para tomar o lugar da harpa como base rítmica com maiores possibilidades nos conjuntos da época. Esta nova estrutura instrumental do tango formado por violino, flauta e guitarra, haveria de permanecer quase inalterada até o advento do bandoneón alemão (SIERRA, 2010, p. 19, tradução nossa).

Todavia, esse processo não fora linear e monolítico: a introdução do bandoneón não significou o esquecimento da guitarra. Desde o final do século XIX até o início do XX, não se pode dizer que o tango já não se constituísse em um espaço semiótico, mobilizando sistemas de signos como a música e a dança dentro de um contexto que evoluiu dos arrabaldes e dos cafés até o advento de uma indústria fonográfica que, incipiente nas primeiras décadas, resultaria em um fator preponderante na difusão mundial do tango.

$\mathrm{E}$, nesse processo, a presença da guitarra não foi eclipsada pelo bandoneón: Carlos Gardel, por exemplo, grava inúmeros tangos tendo a guitarra como protagonista, e, ainda hoje, persistem diversas formações musicais que mantêm essa estrutura de um cantor, acompanhado por uma ou mais guitarras. Portanto, a centralidade que o bandoneón viria a assumir no sistema-tango seria menos decorrente de um processo linear de substituição da guitarra do que pelo caráter estruturante que o bandoneón passaria a adquirir na configuração dos instrumentos que se aglutinavam na formação das orquestras típicas ${ }^{3}$ que, por sua vez, propiciariam um processo gradual no desenvolvimento musical e rítmico do tango.

A despeito dessa centralidade que viria a ocupar o bandoneón, quando se busca uma genealogia na formação instrumental do tango, o contexto ibérico encontra-se perfeitamente adequado à função rítmica que desempenha a guitarra nas planícies pampeiras da região do Rio da Prata, traduzido na figura do gaúcho e do payador ${ }^{4}$, chegando inclusive a atravessar todo o século XX como um elemento sonoro tipicamente tanguero como ainda se assiste em diversas formações instrumentais contemporâneas.

2 Tecnicamente, não será propriamente o bandoneón senão o piano que substituirá a guitarra, mas é a sua entrada que provoca uma reorganização do espaço semiótico do tango inclusive com a formação das orquestras típicas.

3 A partir dos anos de 1920, as orquestras típicas já estavam consolidadas em torno do bandoneón e possibilitaram, principalmente na forma paradigmática dos sextetos (dois bandoneones, dois violinos, contrabaixo e piano), uma evolução gradual da linguagem do tango.

4 Etimologicamente, a payada pode ser traduzida como trova, assim como o payador por trovador, sendo este uma figura arquetípica dentro do contexto da cultura gaúcha, presente na Argentina, Uruguai e no Rio Grande do Sul. 
A sonoridade da guitarra remete a sua origem andaluza, mas, na vastidão das planícies e na figura solitária e nômade do gaúcho, a guitarra ajusta-se ao acompanhamento da poesia cantada de improviso, e que, sob a forma de um duelo, adquire uma função dialógica em que cada payador responde à pergunta que se lhe coloca tal como o fazem os repentistas. Em sua apropriação semiótica, a guitarra reúne o signo do gaúcho e do criollo ${ }^{5}$ como se observa na cumplicidade que Borges (1974, p. 953, tradução nossa) enuncia no prólogo de Para las seis cuerdas: ${ }^{6}$

[...] toda leitura implica em colaboração e quase cumplicidade. [...] no Martín Fierro, um vaivém de bravatas e de lamentos, justificados pelo propósito político da obra, mas totalmente alheias à índole sofrida dos campesinos e aos cautelosos modos do payador. No modesto caso de minhas milongas, o leitor deve suprir a música ausente pela imagem de um homem que cantarola, no umbral de seu portão ou em um armazém, acompanhando-se da guitarra. A mão demora-se nas cordas e as palavras contam menos que os acordes.

Apesar de sua origem europeia, a guitarra desempenha uma função territorializante crucial ao mobilizar elementos semióticos do contexto regional dos pampas nas figuras dos payadores e dos gaúchos. A sonoridade trivial e ibérica, e, paradoxalmente mais universal da guitarra, haveria de ser substituída pela originalidade explosiva do bandoneón. Nesse sentido, como afirma Zucchi (1998), não somente a guitarra, senão os demais instrumentos que o precederam na composição dos primeiros conjuntos de tango, como o violino, a flauta, ou mesmo posteriormente o piano, possuíam uma tradição europeia, herdada de uma prévia experiência em outros gêneros musicais, de modo que a intromissão do bandoneón no contexto da formação instrumental do tango possa ser vista como a introdução de um sentido novo na estruturação de um gênero musical.

Por que um instrumento recém-chegado, do qual nada se sabia, nem sequer pronunciar seu nome, meteu-se assim como uma facada no coração mole, sendo como era e é de tão difícil manejo, quando, muito antes, alguns membros de sua família musical, como o acordeão, a popular verdulera, já estavam à disposição dos menestréis de rua e de boliche [bar]. Teria sido porque sua voz e somente ela, podia expressar a profundidade sentimental que o tango estava buscando anunciar e as suaves tintas do violino, da flauta e da guitarra não alcançavam? Ou teria o bandoneón, com a densa e sombria gama de sua paleta sonora, tomado o tango de sobressalto? (ZUCCHI, 1998, p.1, tradução nossa).

5 Originalmente, trata-se do elemento ibérico nascido nas colônias espanholas. O criollo opõe-se ao imigrante europeu que passa a habitar a região do estuário do Prata a partir do final do século XIX. Aproxima-se da figura do gaúcho, configurando-se em elemento típico da nacionalidade argentina, muito embora, seja igualmente comum ao Uruguai e ao sul do Brasil.

6 Para las seis cuerdas (1965) é um conjunto de poemas sob a forma de milongas. Algumas, inclusive, viriam a ser gravadas por Astor Piazzolla y su Quinteto Nuevo Tango (1965) no disco El Tango. 
Do ponto de vista semiótico, o bandoneón constitui-se então como um processo explosivo, como uma possibilidade de geração de novas linguagens, a partir da imprevisibilidade de sua chegada ao sistema-tango. Já na passagem do século XIX ao $X X$, estava em curso uma evolução gradual na composição rítmica dos instrumentos que compunham o espaço semiótico do tango. Em torno do violino, gravitavam instrumentos como a harpa, o bandolim, a concertina, o acordeão e a gaita, até que houvesse certa estabilidade na configuração dos trios de violino, guitarra e flauta que teria assegurado uma disposição rítmica veloz, de execução rápida, que seria comumente traduzida por uma dança alegre e saltitante, mas que, no entanto, carregava diversos traços musicais que poderiam ainda ser confundidos ora com influências de matriz mais africana, como o candombe, ora com inspirações de matriz rural, como o chamamé e a milonga. Uma matriz africana e uma matriz rural eram elementos que não combinavam com o destino urbano do tango, fortalecendo a hipótese de que o bandoneón iria mobilizar um movimento de tradução desses elementos semióticos de um contexto periférico para uma centralidade.

Trata-se de um único, mas também duplo movimento: o sistema cultural do tango divide-se em dois subsistemas: um subsistema central, que corresponde tanto à configuração geopolítica do elemento urbano (Buenos Aires e, em alguma medida, Montevidéu) como à posição de dominância semiótica que o bandoneón passa a assumir nesse sistema mais amplo; e um subsistema periférico em que se situam os ritmos de matriz africana e rural.

Enquanto o elemento rural é antes periférico, por angariar as forças do interior que se movem rumo ao centro, o africano é periférico por representar basicamente o elemento negro numa sociedade elitista e estratificada econômica e socialmente, reduzindo gradativamente sua importância na formação rítmica do tango.

A rigor, o elemento rural jamais será totalmente suplantado pelo urbano na mesma medida em que a guitarra não será ultrapassada pelo bandoneón, mas terá que se dobrar a uma progressiva situação de coadjuvante na evocação de um passado rural ou arrabalero ao fornecer uma fonte inesgotável de inspiração para ritmos e letras, ainda que mantendo certa autonomia com relação a esse subsistema central que o bandoneón e o elemento citadino assumem na evolução do tango. Para garantir sua sobrevivência no espaço semiótico do tango, a guitarra não cessará de extrair sua força do elemento gaúcho, seja em sua forma mais rústica e rural, seja em sua viagem rumo à cidade, em que junto ao arrabalde protagonizará uma mitologia povoada de corajosos compadritos armados com punhais em suas peripécias borgeanas.

Bandoneón e guitarra irão eventualmente se encontrar, rememorando uma sonoridade rural que o chamamé já desempenhava, utilizando-se do mais alegre acordeão no lugar do lamuriento bandoneón, e que a milonga tornará mais urbana se aproximando do tango. A guitarra, porém, manterá sua relativa autonomia, não se sujeitando demasiadamente à soberania do bandoneón que arregimentará em torno de si o violino, o piano e o contrabaixo na formação das orquestras típicas. 
Desse modo, o tango, naquilo que guarda com a milonga - e que não é pouco -, estará sempre se remetendo ao contexto gaúcho, à trova do payador e sua inseparável guitarra, enquanto a sonoridade mais percussiva trazida pelo candombe dos negros transmutará em elementos sincopados, esvanecendo-se a possibilidade de recuperar seus traços originais. Será preciso realizar certo esforço para identificar o elemento negro no tango, cuja temática nada lhe recorda e que se melhor percebe no acento rítmico de certos arranjos, nas eventuais batidas da mão sobre a caixa dos instrumentos, e em certas figuras da dança quando se exacerbam os cortes e quebradas.

\title{
Descontinuidade e explosão gerando territorialidade
}

Candombe, chamamé, milonga, além da influência da valsa europeia, da polca, da mazurca... Apesar dessa miscelânea de aportes rítmicos e da diversidade de instrumentos terem gerado uma densidade semiótica suficientemente capaz de qualificar o tango e garantir sua continuidade, será a imprevisível introdução do estrangeiro bandoneón que provocará uma descontinuidade na comunicação entre esses elementos rítmicos relativamente estáveis, explicitando a estrutura sincrônica do sistema-tango.

\begin{abstract}
Tanto os processos explosivos como os graduais assumem importantes funções numa estrutura sincrônica: alguns asseguram a inovação, outros a continuidade. Na visão contemporânea, estas tendências são percebidas como hostis, e a luta entre elas é pensada como uma batalha até a última gota de sangue. $\mathrm{Na}$ verdade, elas formam as duas partes de um único e coerente mecanismo da estrutura sincrônica. A agressividade de uma delas não sufoca senão estimula o desenvolvimento da tendência oposta (LÓTMAN, 1999, p. 27, tradução nossa).
\end{abstract}

A convivência desses distintos processos é plenamente observável no sistema-tango. Ainda que a introdução do bandoneón no escopo dos instrumentos musicais tenha significado o estabelecimento de um padrão sonoro ao tango, imprimindo, por exemplo, um tom mais lento e melancólico que se refletirá na dança e nas letras das canções, não impedirá o afastamento de certas tendências opostas que já se colocavam em curso como o uso das guitarras no acompanhamento das canções ao estilo dos payadores e, acima de tudo, nas composições de Carlos Gardel.

Apesar de antagonizarem, bandoneón e guitarra fazem parte de uma mesma estrutura sincrônica de produção de sentido no sistema-tango. Hierarquicamente, contudo, o fator explosivo do bandoneón vai resultar, inicialmente, em uma ruptura enquanto efeito da presença de um elemento estrangeiro que inovará a sintaxe do tango, e, posteriormente, ao assentar-se na centralidade de uma memória, garantirá sua estabilidade e continuidade na formação de um padrão sonoro que organizará as orquestras típicas de tango, de modo que, o que antes era estrangeiro e imprevisto, tornar-se-á próprio e, em certa medida, 
previsível enquanto linguagem sonora. No que se refere à utilização da guitarra, esta se manterá como subsistema dentro do espaço semiótico, assegurando a continuidade de uma tradição que antecede ao próprio tango.

Ritornelo: quando Piazzolla descreve a jornada do bandoneón como um instrumento que tem sua origem em funções religiosas na Alemanha oitocentista para chegar aos bordéis de Buenos Aires ainda no final daquele século, revela-se também a especificidade e hibridez de seu timbre capaz de se desdobrar em sintaxes musicais singulares ao traduzir contextos sonoros tão díspares como o religioso e o prostibular. E se um instrumento, a despeito de suas apropriações por diversos contextos, carrega um pouco de terra, demarcando um território e realizando um agenciamento territorial, o bandoneón viria a encontrar seu próprio espaço semiótico ao expressar a linguagem portuária do Rio da Prata.

Com efeito, onde Lótman localiza apenas uma oportunidade de correspondência entre espaço e território, ${ }^{7}$ pode-se encontrar o próprio fundamento da tipologia da cultura do tango. Não serão poucas as tentativas de fazer coincidir as fronteiras do espaço semiótico do tango com as do estuário do Rio da Prata em um mesmo agenciamento territorial que conjugaria as forças expressivas de um fenômeno estético com as forças centrípetas da geopolítica exercida pelos portos de Buenos Aires e Montevidéu às quais o bandoneón desempenharia o papel de elemento tradutor do contexto em linguagem musical.

O bandoneón pretendia sofisticar o exercício da tradução. Mas continuava sendo um instrumento bastardo. Para se livrar dessa condição, precisava de outro contexto. Começou a falar um novo idioma na Argentina, na qual adentra sem documento. O nome de quem o trouxe ficou eclipsado. A única certeza é que chegou a Buenos Aires e, como milhões de imigrantes, aprendeu a língua do porto e se submeteu a sua lógica: a hibridez. Aqui, o bandoneón encontrou uma nova família organológica, a do tango, com a qual adquiriu outro estatuto, impregnando-lhe a essa música uma sonoridade definitiva (FISCHERMAN; GILBERT, 2009, p. 28, tradução nossa).

O bandoneón não apenas possibilitaria ao tango que desenvolvesse uma nova linguagem a partir de outro universo rítmico, mas guardaria uma ambivalência, uma aura de mistério, cuja adoção não poderia ser explicada por um encadeamento causal de fatores musicais ou sociais. A expressiva afluência de imigrantes que fazia de Buenos Aires uma cidade de estrangeiros, dividida entre um centro rico, oligárquico e conservador, e uma periferia pobre, imigrante e profícua, indicava o germe de uma cultura mestiça. Podia também sugerir a importância que o território desempenharia na conformação de uma tipologia da cultura.

E, de fato, o tango já respondia a essas promessas. Significava uma mistura de ritmos e linguagens que comunicava as origens de seus componentes: a guitarra dos payadores,

7 "Quando a semiosfera também envolve características reais do território, a fronteira é espacial no sentido literal" (LÓTMAN, 1990, p. 140, tradução nossa). 
o acordeão dos italianos, a dança relativamente alegre para compensar a vida desgastante que se levava. Significava também um progressivo movimento centrípeto que agenciava as forças dispersas em torno da passagem desses componentes do meio para um território comum, possibilitando atribuir consistência a esses elementos heterogêneos e imprimir um novo sentido aos textos culturais que adquiriam uma nova função nesse contexto.

Tudo isso poderia ser previsível: a aparição de uma cultura mestiça com tendências a uma tipificação centrada no território, primeiro como um agenciamento das próprias forças expressivas de um fenômeno estético, depois como agenciamento de forças geopolíticas. O imprevisível era a escolha do bandoneón como artífice do destino do tango. Se a presença do acordeão no contexto do tango - assim como no âmbito mais amplo do gaúcho - parece ter sido uma herança da massiva imigração italiana que se inicia na segunda metade do século XIX, essa proximidade sonora não explica senão problematiza a consolidação do bandoneón como o instrumento basilar do tango, colocando outros elementos semióticos em jogo nesse processo de formação de um espaço semiótico próprio.

Se o tango demandasse uma nova qualidade sonora para consolidar uma linguagem própria, poderia tê-la adquirido por meio do aporte do acordeão que, assim como o bandoneón, pertence à mesma família de instrumentos aerófonos. No entanto, a sonoridade do bandoneón acabou sendo apropriada e desenvolvida ao gosto do tango rio-platense, ou mais propriamente portenho ou montevideano, ainda que seus fabricantes alemães tivessem buscado adequá-lo às interpretações sacras e de concerto e não às supostas investidas profanas aos bordéis ou à intimidade da proximidade dos corpos.

Esse agenciamento territorial que sofre o bandoneón na sua jornada de apropriação pelo tango não se reduz a um mero deslocamento de seu país de origem para as cidades portuárias do estuário do Rio da Prata. Não é esse transporte geográfico que lhe assegura sua condição de estrangeiro, senão a recíproca modelização que ele faz do e pelo tango: o bandoneón modeliza a linguagem do tango, mas também o tango modeliza a linguagem do bandoneón.

Na medida em que o timbre está associado à qualidade sonora de cada instrumento, ele representa seu traço diferencial ou a qualidade semiótica que o diferencia dos demais. Instrumentos diferentes tocando a mesma nota soam distintamente, pois vibram em múltiplos de frequência diferentes, e assim o fazem porque a morfologia, ou seja, a arquitetura funcional assim o permite.

No entanto, mesmo que as características do timbre do bandoneón provenham de sua morfologia, esta não se encontra imune a variações decorrentes do seu processo de fabricação como o uso de materiais mais ou menos nobres, ou em escalas diferenciadas. Nesse sentido, pode-se dizer que o próprio tango modelizou o bandoneón, quando se sabe que, em dado momento, os instrumentistas rio-platenses passaram a fazer exigência dos fabricantes de uma escala diatônica sui-generis e modificaram constantemente sua afinação até 1928 . 
Por outro lado, a habilidade técnica do instrumentista e seu modo de interpretar com o uso de certos fraseados também modelizou o tango ao Ihe imprimir uma sintaxe própria. Essa combinação da introdução de um novo timbre e de uma nova sintaxe resultará na consolidação de um padrão que chegará ao ponto de permitir que sua sonoridade seja confundida com a do próprio tango.

Mas para chegar a ter um selo próprio, distinto, com uma personalidade definida, o tango encontra-se magicamente com o instrumento que dará a sua identidade definitiva: o bandoneón. Sem dúvida é um instrumento estranho para esses lugares e essas pessoas, tanto aos nativos como aos imigrantes, que não se sabe com precisão quem o trouxe, com quem chegou num barco, mas que o portenho adota e adapta (MARTíNEZ; ETCHEGARAY; MOLINARI, 2011, p.141, tradução nossa).

\section{A resistência ao estrangeiro}

O processo explosivo na consolidação do espaço semiótico do tango a partir da introdução do bandoneón no sistema de signos da música consiste na imprevisibilidade de sua chegada, não fazendo parte de um conjunto de possibilidades que se encontravam disponíveis naquele momento e lugar. Estrangeiro na comunicação e ao sistema cultural que já se encontrava em formação, o bandoneón irá surpreendentemente estruturar esse espaço, tornando-o próprio, não simplesmente porque veio de fora - posto que, a rigor, todos os demais instrumentos que configuraram o tango também o vieram -, mas porque soube interagir com os demais elementos e consolidar um núcleo próprio, impondo seus traços distintivos. O caráter explosivo e a condição de estrangeiro do bandoneón também são notáveis pelo efeito inverso que inicialmente causa em sua passagem de um meio a outro, ou seja, em sua negação como um elemento estranho às características que o tango já assumira na virada do século XIX para o XX.

Pensando em como teria ocorrido esse processo de introdução do bandoneón no escopo de instrumentos do tango no início do século XX, o bandoneonista argentino Pablo Mainetti conjectura:

[...] posso imaginar os conflitos naquela época, se era ou não era... Os tradicionalistas teriam dito "Isto não é tango", como sempre ocorre quando existe uma mudança. Nessas épocas, os bandoneonistas primitivos eram pessoas que começavam a pesquisar, a estudar e a tocar com as descobertas alcançadas. Hoje, já existe uma técnica depuradíssima [...] Há gente que controla o instrumento muito bem, é só pensar que se trata de um instrumento alemão e os alemães vêm estudá-lo aqui (GASIÓ, 2011, p. 4006, tradução nossa). 
Isto não é tango! Haveria então de ser essa a contrassenha diante das mudanças que, soando como ameaças ao espaço semiótico do tango, estariam por se repetir - e que, sobretudo contra Piazzolla, passariam ainda a ser desferidas ostensivamente. Paradoxalmente, o instrumento que definiria os traços distintivos do tango desenhou um longo percurso até ser aceito como padrão, mantendo-se como um estrangeiro a um sistema cultural que ele próprio o funda. A chegada do bandoneón foi possivelmente a primeira ruptura que, como uma explosão, daria assento definitivo ao tango. Outras estariam por vir, tensionando os limites do espaço semiótico do tango nas dobras entre o próprio e o estrangeiro.

Paulo Masella Lopes é doutor e mestre em Ciências da Comunicação pela ECA-USP; bacharel e licenciado em Filosofia pela FFLCH-USP.

paulomasella@gmail.com

\section{Referências}

BORGES, J. L. Obras completas 1923-1972. Buenos Aires: Emecê, 1974.

FISCHERMAN, D.; GILBERT, A. Piazzolla el mal entendido: un estudio cultural. 1a. ed. Buenos Aires: Edhasa, 2009.

GASIÓ, G. La historia del tango 20: siglo XXI: década 1: $1^{\circ}$ parte. 1a. ed. Buenos Aires: Corregidor, 2011.

LÓTMAN, I. Universe of the mind. A semiotic theory of culture. Translated by Ann Shukman. Bloomington: Indianopolis University Press, 1990.

Cultura y explosión. Lo previsible y lo imprevisible en los procesos de cambio social. Barcelona: Gedisa, 1999.

MARTÍNEZ, R. L.; ETCHEGARAY, N. P.; MOLINARI, A. De la vigüela ao fueye: las expresiones culturales argentinas que conducen al tango. 2a. ed. Buenos Aires: Editorial de la Cultura Argentina Urbana, 2011.

PIAZZOLLA, A. The Central Park Concert. USA: Chesky, 1987-1994.

. Astor Piazzolla y su Quinteto Nuevo Tango (1965). El Tango - Piazzolla-Borges (voz de Edmundo Rivero). Argentina: La Laida Editora-Universal Music, 2005.

SÁBATO, E. Tango - discusión y clave. 3a. ed. Buenos Aires: Editorial Losada, 2005.

SIERRA, L. A. Historia de la orquesta típica: evolución instrumental del tango. $2^{\text {a }}$ edición. Buenos Aires: Corregidor, 2010.

ZUCCHI, O. El tango, el bandoneón y sus intérpretes. Tomo I. Buenos Aires: Corregidor, 1998. 